\title{
Factors affecting under-five diarrhea in households with dirt floors: a multilevel mixed-effects analysis from a national survey of Ethiopia
}

Biniyam Sahiledengle ( $\sim$ biniyam.sahiledengle@gmail.com )

Madda Walabu University Goba Referral hospital, Department of Public Health, Bale-Goba, Ethiopia https://orcid.org/0000-0002-1114-4849

\section{Abera Kumie}

Department of Community Health, College of Health Science, Addis Ababa University

\section{Daniel Atlaw}

Madda Walabu University Goba Referral hospital, Department of Human Anatomy, Bale-Goba, Ethiopia

\section{Yohannes Tekalegn}

Madda Walabu University Goba Referral hospital, Department of Public Health, Bale-Goba, Ethiopia

\section{Demelash Woldeyohannes}

Department of Public Health, College of Medicine and Health Science, Wachemo University, Hossana,

\section{Ethiopia}

\section{Demisu Zenbaba}

Madda Walabu University Goba Referral hospital, Department of Public Health, Bale-Goba, Ethiopia

\section{Tadesse Awoke}

University of Gondar, Department of Epidemiology and Biostatistics, College of Medicine and Health Sciences, Institute of Public Health, Gondar, Ethiopia

\section{Research Article}

Keywords: Sub-optimal flooring, Diarrhea, Earth Floor, Dirt Floor, Ethiopia

Posted Date: June 23rd, 2021

DOI: https://doi.org/10.21203/rs.3.rs-646901/v1

License: (a) (1) This work is licensed under a Creative Commons Attribution 4.0 International License. Read Full License 


\section{Abstract}

Introduction: Diarrhea remains the second leading cause of mortality among under-five children in Ethiopia, spreads more easily in homes with dirt floors. Even though the determinants of diarrheal illness is widely recognized at the global level, there is a limited number of studies that identified the individual and community-level factors solely among children residing in households with sub-optimal flooring (i.e. earth, mud or sand, and dung). Therefore, this study aims to identify individual and community-level factors associated with childhood diarrhea in households with sub-optimal flooring in Ethiopia.

Methods: Data from the fourth round of the Ethiopian Demographic and Health Survey (EDHS) conducted in 2016 is used to carry out the analysis. The EDHS was large, cross-sectional by design, and nationally representative. A total of 9,097 under-five children living in households with sub-optimal floors and 645 community clusters were included in the current analysis. A multi-level logistic regression analysis was used to examine both individual and community level factors while accounting for the hierarchal structure of the data.

Results: The overall prevalence of childhood diarrhea in households with suboptimal flooring in Ethiopia was $11.9 \%$ (95\% Cl:11.2-12.6). Children aged 6-11 months (adjusted OR [AOR]=2.68, 95\%Cl: 1.89-3.82), and $\geq 12$ months ( $A O R=1.65,95 \% \mathrm{Cl}: 1.22-2.24$ ) were more likely to have diarrhea compared with children aged 0-5 months. Having cough ( $\mathrm{AOR}=6.09,95 \% \mathrm{Cl}=4.93-7.52)$ and fever $(\mathrm{AOR}=1.62,95 \% \mathrm{Cl}: 1.30-2.01)$ were found to increase the risk for the development of diarrhea in children. Maternal age (25-34 years) and paternal lack of educated were found to be associated with lower odds of childhood diarrheal prevalence rates. Further, children from households with higher family size ( $\geq 5$ family size), low birth order (firstborn), and the number of under-five children (2-3 children) were reported decreased odds of diarrhea. At the community level, children living in pastoralist regions (such as Afar and Somali region) significantly less likely to have diarrhea vulnerability (AOR: $0.61,95 \% \mathrm{Cl}: 0.40-0.91$ ) compared to those who reside in cities.

Conclusion: Both individual-level (age of the child, birth order, presence of cough and fever, maternal age, paternal education, household size, improper child stool disposal, number of under-five children) and community-level factor (place of residence) were revealed to be important factors for childhood diarrhea in households with suboptimal flooring.

\section{Introduction}

Diarrhea causes more than half a million childhood mortality across low-income and middle-income countries (LMICs) [1]. According to the Global Burden of Disease Study 2017, more than 910 million childhood diarrheal cases were reported each year [2]. Globally, diarrhea remains a leading cause of under-five mortality-account for 1 in 9 child deaths [3]. In addition to this staggering loss of under-five life, it can have a detrimental impact on childhood growth and cognitive development $[4,5]$. It is also 
estimated that the odds of stunting at 24 months increased by $5 \%$ with each diarrheal episode [6]. Furthermore, the proportion of reported antibiotic use among sick children under 5 years of age with fever, diarrhea, or cough was less than fifty percent, $43.1 \%$ [7].

Diarrhea is preventable with the application of hand hygiene, basic sanitation, and the provision of safe drinking water [8]. Almost $88 \%$ of diarrhea-associated deaths are attributable to unsafe water, inadequate sanitation, and insufficient hygiene [9]. Several studies explore the effect of single and combined water, sanitation, and hygiene (WASH) intervention in the reduce risk of diarrheal morbidity [8,10-14]. For example, a systematic review for the effect of WASH interventions for acute childhood diarrhea found that various WASH interventions show diarrhea risk reductions between $27 \%$ and $53 \%$ in children under five years old, depending on intervention type [11]. A recent updated meta-analysis showed that promoting handwashing with soap associated with reduced risk of diarrhea by $30 \%$ [14].

In Ethiopia, where there is a lack of safe excreta disposal facility, safe drinking water, and poor hygiene practice $[8,15,16]$, diarrhea remains is an important public health problem. Over the past two decades, the prevalence of childhood diarrhea has shown a declining trend-from $24 \%$ in 2000 to $12 \%$ in 2016 [17,18]. Despite progress in the reduction of childhood diarrhea in Ethiopia, still it is the second leading cause of morbidity and mortality among under-five children next to pneumonia [15,18]. A recent systematic review finding revealed that the pooled prevalence of diarrhea among under-five children in Ethiopia was $22 \%$ [19].

Different studies showed that household-level risk factors such as lack of safe water and improved sanitation facility, poor maternal hygiene, household water treatment, methods of complementary feeding, types of water storage equipment, maternal education, and improper waste disposal practices were significant factors for the occurrence of diarrheal illness $[8,10,12,13,15,19,20]$. In previous works of literature, the effect of improved WASH on childhood diarrhea morbidity was well established. However, in some instances, WASH interventions fail to appear long-term impact [21], due to reinfection and contamination of the living home as a result of dirt floors. As dirt floors facilitate and increased defilement of finger, fluid, food, and materials that encounter these surfaces and possibly increase the risk of diarrhea among children [21-24]. A study from Zimbabwe showed that mothers of infants living in households with improved flooring were less likely to report diarrheal illness. Further, the association between flooring and diarrheal illness did not vary by the presence of improved/unimproved water or sanitation [23]. It was also found that dirt and mud floors are a known predictor of diarrhea and parasitic infestations $[23,24]$. Eliminating a dirt floor from the home results in dramatic reductions in childhood diarrhea and Soil-Transmitted Helminth (STH) $[23,25]$. For instance, replacing a dirt floor with a concrete floor reduces diarrhea by $49 \%$ [26].

In many developing countries, including Ethiopia replacing a dirt floor with concrete or other improved material is unaffordable to the poor. And the challenges remain due to cleaning of sand or soil floors are so difficult, the proximity of latrine pits, and unsanitary environmental surrounding. This may be further exacerbated by contamination of the floor by fecal matter brought in on shoes, and especially when 
animals live in close proximity to humans $[22,27,28]$. According to the recent 2016 EDHS report, the two most commonly used materials for flooring in Ethiopia are earth or sand (48\%) and dung (33\%) [18]. And children dwelling in households with mud floors are disproportionately affected by diarrheal diseases [29].

Numerous research articles from Ethiopia have identified the determinants of under-five diarrhea $[15,19,29,30]$. However, specific studies that focus on factors that influence childhood diarrhea in households with sub-optimal flooring (i.e. earth, mud or sand, and dung) are limited and not sufficient to show the underlying factors. As more than $80 \%$ of Ethiopians live and sleep on a dirt floor, the challenges remain enormous where diarrhea is spreads more easily in homes with dirt floors. Up to date, no study ever assessed the determinants of diarrhea solely among children residing in households with the suboptimal floor in Ethiopia. Therefore, this present study aimed to investigate factors associated with childhood diarrhea among children residing in households with sub-optimal flooring in Ethiopia.

\section{Methods}

\section{Data Sources}

The data source for this analysis was the 2016 Ethiopia Demographic and Health Survey (EDHS) [18]. It is a nationally representative household survey carried out based on a nationally representative sample of households that provide estimates at the national and regional levels. The datasets of EDHS surveys are freely available, and we have accessed it from the online repository of the Demographic and Health Survey (DHS) Program website upon request via a link https://www.dhsprogram.com/data/availabledatasets.cfm.

\section{Study design and sampling}

The 2016 EDHS was cross-sectional by design. The sample in EDHS was designed to provide population and health indicators at the national and regional levels. The EDHS used a stratified two-stage cluster sampling technique. In the first stage, 645 enumeration areas (EAs) (202 urban and 443 rural areas) were selected with probability proportional to the EA size. Then, household listing was done for the selected EAs. In the second stage, a fixed number of 28 households per cluster were selected using the newly created household list as a sampling frame [18]. In this study, we included all under-five children living in households with suboptimal floor. A total of 9,097chidren from sub-optimal floor households and 645 community clusters were included in the current analysis (Figure 1)..

\section{Outcome variable}

The outcome variable for this study was presence of diarrhea. Diarrhea was defined as the passage of 3 or more loose or liquid stools per day, or more frequently than is normal for the individual. In the EDHS, 
mothers are asked if their children under five had diarrhea in the past 2 weeks prior to the survey. The response was recorded as "yes" and "no".

\section{Independent variables}

The individual- and community-level variables included in the study are shown in Table 1, along with the coding and definitions.

\section{Data analysis}

Data analysis was carried out using STATA version 14 (Stata Corp, College Station, Texas, United States) statistical software. We used the "svy" command to weight the survey data as per the recommendation of the EDHS. Sample weights were applied in order to compensate for the unequal probability of selection between the strata that were geographically defined, as well as for non-responses. A detailed explanation of the weighting procedure can be found in the EDHS methodology report [10]. The EDHS data are hierarchical (children were nested in clusters). Children from the same cluster will be more similar to each other than children from different clusters. For this reason, we used a multilevel model which account the hierarchical nature of the EDHS data [31]. Accordingly, four models were fitted to estimate both fixed effects of the individual and community-level factors and random effect of between-cluster variation. Null model (model 0): This model was run without any independent variables, to test the random effect of between-cluster variation on childhood diarrhea. Derived from the between-cluster and within-cluster variability. The intercept only model was used to estimate intra-class correlation (ICC) to determine if data justified using a multilevel approach was possible or not. Individual level factors (model I): The second model examined effects of individual level characteristics on childhood diarrhea among children living in households with sub-optimal flooring. Also, ICC was estimated and observed if there was a decline in the between - cluster variability upon adding individual factors to the empty model. Percentage change in variance (PCV) was calculated with reference to null model to look at relative contribution to explain childhood diarrhea. Community-level factor model (model II): This model contained only characteristics of cluster. This model allows us to examine whether the community level variables explain between cluster variations on childhood diarrhea. Similarly, ICC was estimated and its change from null model was assessed. Combined model (model III): Important characteristics of individual and community level variables were simultaneously fitted to one model to reveal the net fixed and random effects.

Model fits were assessed using log-likelihood (LL), deviance, and Akaike Information Criterion (AIC). Loglikelihood (LL), AIC, and deviance were used to estimate the goodness of fit of the adjusted final model in comparison to the preceding models (individual and community level model adjustments). The LL, AIC, and deviance value for each subsequent model was compared and the model with the highest value of $\mathrm{LL}$ and lowest value of deviance and AIC was considered to be the best fit model. Variables that had a relationship with childhood diarrhea $(p<0.20)$ were considered for the final model [32]. Adjusted ORs (AOR) with a $95 \% \mathrm{Cl}$ (Confidence Interval) were used to declare statistical significance. 


\section{Ethics approval}

DHS Programme granted permission to download and use the data for this study after being registered and submitting a request with briefly stated objectives of the study. The Institution Review Board approved procedures for DHS public-use data sets that do not in any way allow respondents, households, or sample communities to be identified. There are no names of individuals or household addresses in the data files. The detail of the ethical issues has been published in the 2016 EDHS final report, which can be accessed at: http://www.dhsprogram.com/publications.

\section{Results}

\section{Characteristics of study participants and childhood diarrhea prevalence}

Table 2 shows the descriptive data of the respondents. Of the 9,097 children included in the analysis, half $(n=4,646,51.1 \%)$ were male. The majority $78.4 \%$ of the children were aged 12 months or older and $70.7 \%$ currently breastfed. Over $70.4 \%$ of mothers of the children had no formal education, almost three-fourth of them were agricultural employees, and $52.9 \%$ were in the poor wealth quintile. The majority of study participants, $(n=8,681,95.4 \%)$ were rural dwellers, $52.3 \%$ of the respondents use unimproved drinking water sources, and $94.5 \%$ use unimproved sanitation facilities. The overall prevalence of childhood diarrhea in households with suboptimal flooring in Ethiopia was 11.9\% (95\% Cl:11.2-12.6).

\section{Factors associated with childhood diarrhea in households suboptimal flooring in Ethiopia}

On bivariable multilevel logistic regression analysis, child's age, number of under-five children, currently breastfeeding, cough in the last two-week, child stool disposal, mother's age, mother's education level, respondent currently working, paternal education, household size, wealth quintiles, region, and ecological cluster were associated with childhood diarrhea. However, in the final model at the individual level (child's sex, child's age, number of under-five children, birth order, fever in the last two-week, cough in the last twoweek, child stool disposal, mother's age, paternal education, and household size) and at community level region were significantly associated with diarrhea among children's in households suboptimal flooring in Ethiopia $(p<0.05)$ Table 3.

Table 4 and 5 displayed the adjusted estimates of selected factors on childhood diarrhea. The result from model 4 (final model) revealed that women whose children were aged 6-11 months ( $A O R=2.68,95 \% \mathrm{Cl}$ $=1.89-3.82)$ and $\geq 12$ months $(A O R=1.65,95 \% \mathrm{Cl}=1.22-2.24)$ were more likely to have diarrhea compared with those whose children were aged 0-5 month. The odds of diarrhea among children in households with $2-3$ under-five children were $20 \%$ lower $(A O R=0.80,95 \% \mathrm{Cl}=0.66-0.98$ ) compared to children living in households with single or less under-five children. The odds of diarrhea were lower by $47 \%$ among firstborn children compared with their counterparts (AOR: $0.53,95 \% \mathrm{Cl}$ : $0.36-0.79$ ). The odds 
of diarrhea were higher among children having cough $(\mathrm{AOR}=6.09,95 \% \mathrm{Cl}=4.93-7.52)$ and fever $(\mathrm{AOR}=$ $1.62,95 \% \mathrm{Cl}: 1.30-2.01)$ compared with their counterparts. Additionally, compared with children from households that had safe child stool disposal, those from households with unsafe child stool disposal were $29 \%$ lower to have diarrhea (AOR: $0.71,95 \% \mathrm{Cl}$ : 0.57-0.87). The odds of diarrhea were $32 \%$ higher among children whose mothers were 25-34 years old than mothers aged between 35-49 years. In this study, children of an uneducated father were less vulnerable to diarrhea ( $A O R=0.82,95 \% \mathrm{Cl}=0.68-0.99$ ) compared with primary and above-educated ones. The odds of diarrhea were lower among households having five and above family size than those with $1-4$ household member (AOR: $0.66,95 \% \mathrm{Cl}: 0.52-0.85$ )

At the community level, the odds of diarrhea were $39 \%$ lower among children in pastoralists compared to those residing in the city (AOR: $0.61,95 \% \mathrm{Cl}: 0.40-0.91$ ).

\section{Measures of variation (random-effects) and model fit statistics}

Measure of variation (random intercept models) and model fit statistics of diarrhea in households with suboptimal flooring in Ethiopia can see from Table 6. The ICC in the empty model was $10.36 \%$, indicating that $10.36 \%$ of the total variability for diarrhea was due to differences between clusters (Enumeration's areas), with the remaining unexplained $89.64 \%$ which is attributed to individual differences. Additionally, the ICC in the final model (6.0\%) suggested that residual community influences were persistent even after adjusting for the individual- and community-level factors. This implies that there are other unmeasured community factors. In this study, the models were compared with deviance, and model III (a model with both individual and community level factor) was selected, had the lowest deviance $(4,375.15)$ (Table 6)..

Table 6 (Model 4) revealed that the PCV for individual and community level factors model adjustment was $44.7 \%$; indicating that almost $45 \%$ of the variance in the odds of diarrheal morbidity among underfive children was explained by individual and community-levels factors found in the model. Moreover, the MOR indicated that diarrhea was attributed to community-level factors. The MOR for under-five diarrhea was 1.79 in the empty model (model 1); this showed that there was variation between communities (clustering) since MOR was 1.79 times higher than the reference $(\mathrm{MOR}=1)$. The unexplained community variation in diarrheal morbidity decreased to MOR of 1.54 when all factors were added to the null model (empty model). This indicates that when all factors are included, the effect of clustering is still statistically significant in the full model.

\section{Discussion}

This study identifies factors associated with the prevalence of childhood diarrhea in households with sub-optimal floors in Ethiopia. Our study may be the first to report factors associated with the prevalence of childhood diarrhea in households with sub-optimal flooring in the Ethiopian context. It was found that childhood diarrhea was associated with the age of the child, birth order, presence of cough and fever, maternal age, paternal education, household size, improper child stool disposal, number of under-five children, and place of residence. 
In this study, the odds of diarrhea among children older than 6 months were higher compared with those aged $<6$ months, which was similar to the results of a study done in Rwanda [33], Pakistan [34], and Ethiopia [35]. The possible justifications could be due to the fact that children older than 6 months usually crawling on the ground which increases the probability of getting and contracting filth materials, particularly those live-in households with the mud floor may expose to pathogenic microorganisms easily. In addition, in this age, unhygienic and contaminated food as a result of sub-optimal flooring may increase the risk of diarrhea. On the other hand, younger infants-age less than 6 months would be protected against diarrheal diseases by different mechanisms such as maternal antibodies obtained through exclusive breastfeeding and they are less exposed to the contaminated floor because these ages are neither crawling nor walking and cannot easily pick dirt or other contaminated objects.

A lower risk for diarrhea was found for children in households with 2-3 under-five children. This finding is in agreement with a cross-sectional study conducted in Ethiopia [8]. This might be due to when the number of children in the household increases it is expected that older children may guide younger sibling on hygiene behavior and attention from peer may increase. In contrast, other studies reported an increased risk of diarrheal frequency as the number of children increased $[30,36]$.

In this study, lower birth order was associated with a lower risk of diarrheal morbidity. This finding supported cross-sectional studies conducted in Ethiopia [8,30]. The possible explanation for this may be as the childbirth order increases it is likely that children will be more exposed to diarrhea because the care and attention from parents decrease [30].

Children having cough and fever were found to have increased probability of childhood diarrhea by 6.09 and 1.62-fold, respectively, compared to children without cough and fever in the past 14 days prior to the survey. Having both conditions of cough and fever may increase the risk of diarrhea or the episodes of diarrhea among children may predispose children for cough and/or fever. Due to the nature of the study design, we are unable to determine which occurred first. However, there the relationship could explain the association between pneumonia and diarrhea [37,38]. A study from Ethiopia also identified the positive association between diarrhea and cough, the study indicated the risk of diarrhea was four times higher in children having cough than their counterparts [8].

In this study, a significant association between diarrhea and child stool disposal was found. Somewhat surprisingly, our finding showed that the odds of diarrhea were lower among children whose stool was disposed of unsafe than children whose stools were disposed of safely. We were unable to locate other studies that have examined the relationship between presence of diarrhea and child stool disposal in households with sub-optimal flooring. However, studies reported a positive relationship between unsafe child stool disposal and increased risk of childhood diarrhea [30,39].

Living in the pastoralist area was also found to be protective for developing diarrhea, as compared to those dwelling in cities. This finding can satisfactorily explain by children of pastoralist communities tend to move from place to place, as a result, the risk of fecal-oral disease transmission from contaminated flooring may be minimal as compared to those children who live on earth floor in cities. In 
addition, among city dwellers, children spend much time on the contaminated ground and their exploratory behaviors including geophagia could expose them for diarrheal disease.

In this study, water and sanitation facility failed to be significantly associated with childhood diarrhea. This finding contradicts previous study which reported that unprotected source of drinking water and unimproved latrine were associated with the higher incidence of childhood diarrhea [40]. The possible reason for this discrepancy maybe due to water and sanitation interventions fail to show significant longterm impact in households with sub-optimal flooring, due to reinfection of children with diarrhea as dirt flooring can facilitate contamination. In many case, poor hygiene practices persistent in households with sub-optimal flooring and children were exposed to feco-oral infections regardless of the availability of water and sanitation facilities. Further, this finding has implication on WASH interventions that aimed to reduce childhood diarrhea; in households with sub-optimal flooring WASH intervention alone may not have an impact on childhood diarrhea.

\section{Limitations}

Though the study explored factors associated with childhood diarrhea in households with sub-optimal flooring it has some limitations. Firstly, the analyses were conducted using EDHS data collected in a cross-sectional survey, which prevents causal inferences. Secondly, because the information on childhood diarrhea was self-reported, there is the possibility of recall bias. Third, due to the secondary nature of the data, the present study was limited by unmeasured confounders. Despite these limitations, we used a multilevel model to account for the clustered nature of EDHS data, which enhances the accuracy of estimates.

\section{Conclusion}

This study provides the first empirical evidence on factors associated with the prevalence of diarrhea in children residing in households with sub-optimal flooring in Ethiopia. Both individual-level (age of the child, birth order, presence of cough and fever, maternal age, paternal education, household size, improper child stool disposal, number of under-five children) and community-level factor (place of residence) were revealed to be important factors for childhood diarrhea in households with suboptimal flooring. Our results suggest that household improved flooring interventions may yield more sustained reductions in the prevalence of childhood diarrhea. In addition, public health interventions and strategies designed to promote sanitation in households with sub-optimal flooring need to consider the identified factors through community assessments to identify community-specific barriers.

\section{Abbreviations}

AOR: Adjusted odds ratio; AIC: Akaike's Information Criterion; BIC: Bayesian information criteria; $\mathrm{Cl}$ : Confidence interval; COR: Crude odds ratio; DHS: Health and demographic surveys; EDHS: Ethiopian Health and demographic surveys; WHO: World Health Organization 


\section{Declarations}

\section{Availability of supporting data}

The data we used which is the 2016 Ethiopian Demographic and Health Survey was obtained from the DHS program (www.dhsprogram.com) but the 'Dataset Terms of Use' do not permit us to distribute this data as per data access instructions (http://dhsprogram.com/data/Access-Instructions.cfm). To get access to the dataset you must first be a registered user of the website (www.dhsprogram.com) and download the 2016 Ethiopian Demographic and Health Survey.

\section{Competing interests}

The author declares that he has no competing interests.

\section{Funding}

No fund was received for the present review.

\section{Authors' Contribution}

BS: Conceptualizes, design the study and data curation, performed the analysis, wrote and approved the final manuscript. AK, DA, YT, DW, DZ and TA: Contribute to the analysis, critically reviewed the manuscript and approved the final manuscript. All authors read and approved the final manuscript before submission.

\section{Acknowledgments}

The authors acknowledge Measure DHS program for providing the EDHS dataset.

\section{References}

1. Roth GA, Abate D, Abate KH, Abay SM, Abbafati C, Abbasi N, et al. Global, regional, and national agesex-specific mortality for 282 causes of death in 195 countries and territories, 1980-2017: a systematic analysis for the Global Burden of Disease Study 2017. The Lancet. Elsevier; 2018;392:1736-88.

2. Global, regional, and national incidence, prevalence, and years lived with disability for 354 diseases and injuries for 195 countries and territories, 1990-2017: a systematic analysis for the Global Burden of Disease Study 2017 - The Lancet [Internet]. [cited 2021 Mar 30]. Available from: https://www.thelancet.com/journals/lancet/article/PIIS0140-6736(18)32279-7/fulltext 
3. Global Diarrhea Burden | Global Water, Sanitation and Hygiene | Healthy Water | CDC [Internet]. 2018 [cited 2021 Mar 30]. Available from: https://www.cdc.gov/healthywater/global/diarrhea-burden.html

4. Bowen A, Agboatwalla M, Luby S, Tobery T, Ayers T, Hoekstra RM. Association between intensive handwashing promotion and child development in Karachi, Pakistan: a cluster randomized controlled trial. Arch Pediatr Adolesc Med. 2012;166:1037-44.

5. Limitations in Verbal Fluency Following Heavy Burdens of Early Childhood Diarrhea in Brazilian Shantytown Children: Child Neuropsychology: Vol 11, No 3 [Internet]. [cited 2021 Mar 30]. Available from: https://www.tandfonline.com/doi/abs/10.1080/092970490911252?journalCode $=$ ncny20

6. Black RE, Allen LH, Bhutta ZA, Caulfield LE, Onis M de, Ezzati M, et al. Maternal and child undernutrition: global and regional exposures and health consequences. The Lancet. Elsevier; 2008;371:243-60.

7. Allwell-Brown G, Hussain-Alkhateeb L, Kitutu FE, Strömdahl S, Mårtensson A, Johansson EW. Trends in reported antibiotic use among children under 5 years of age with fever, diarrhoea, or cough with fast or difficult breathing across low-income and middle-income countries in 2005-17: a systematic analysis of 132 national surveys from 73 countries. Lancet Glob Health. Elsevier; 2020;8:e799-807.

8. Kumie A. The effect of improved water and sanitation on diarrhea: Evidence from pooled Ethiopia Demographic and Health Surveys-A multilevel mixed-effects analysis. Ethiop J Health Dev.:9.

9. Progress for Children (No. 5) [Internet]. [cited 2021 Mar 30]. Available from: https://www.unicef.org/reports/progress-children-no-5

10. Curtis V, Cairncross S. Effect of washing hands with soap on diarrhoea risk in the community: a systematic review. Lancet Infect Dis. 2003;3:275-81.

11. Darvesh N, Das JK, Vaivada T, Gaffey MF, Rasanathan K, Bhutta ZA. Water, sanitation and hygiene interventions for acute childhood diarrhea: a systematic review to provide estimates for the Lives Saved Tool. BMC Public Health [Internet]. 2017 [cited 2021 Mar 30];17. Available from: https://www.ncbi.nlm.nih.gov/pmc/articles/PMC5688426/

12. Solomon ET, Robele S, Kloos H, Mengistie B. Effect of household water treatment with chlorine on diarrhea among children under the age of five years in rural areas of Dire Dawa, eastern Ethiopia: a cluster randomized controlled trial. Infect Dis Poverty. 2020;9:64.

13. Dey NC, Parvez M, Islam MR, Mistry SK, Levine DI. Effectiveness of a community-based water, sanitation, and hygiene (WASH) intervention in reduction of diarrhoea among under-five children: Evidence from a repeated cross-sectional study (2007-2015) in rural Bangladesh. Int J Hyg Environ Health. 2019;222:1098-108.

14. Wolf J, Hunter PR, Freeman MC, Cumming O, Clasen T, Bartram J, et al. Impact of drinking water, sanitation and handwashing with soap on childhood diarrhoeal disease: updated meta-analysis and meta-regression. Trop Med Int Health. 2018;23:508-25.

15. Trends and determinants of diarrhea among under-five children in Ethiopia: cross-sectional study: multivariate decomposition and multilevel analysis based on Bayesian approach evidenced by EDHS 
2000-2016 data | BMC Public Health | Full Text [Internet]. [cited 2021 Mar 31]. Available from: https://bmcpublichealth.biomedcentral.com/articles/10.1186/s12889-021-10191-3

16. Exploring geographical variations and inequalities in access to improved water and sanitation in Ethiopia: mapping and spatial analysis - ScienceDirect [Internet]. [cited 2021 Mar 31]. Available from: https://www.sciencedirect.com/science/article/pii/S2405844020306733

17. Central Statistical Authority [Ethiopia] and ORC Macro. 2001. Ethiopia Demographic and Health Survey 2000. Addis Ababa, Ethiopia and Calverton, Maryland, USA: Central Statistical Authority and ORC Macro.

18. Central Statistical Agency (CSA) [Ethiopia] and ICF. 2016. Ethiopia Demographic and Health Survey 2016. Addis Ababa, Ethiopia, and Rockville, Maryland, USA: CSA and ICF.

19. Alebel A, Tesema C, Temesgen B, Gebrie A, Petrucka P, Kibret GD. Prevalence and determinants of diarrhea among under-five children in Ethiopia: A systematic review and meta-analysis. PLOS ONE. Public Library of Science; 2018;13:e0199684.

20. Solomon ET, Gari SR, Kloos H, Mengistie B. Diarrheal morbidity and predisposing factors among children under 5 years of age in rural East Ethiopia. Trop Med Health. 2020;48:66.

21. Alum A, Rubino JR, ljaz MK. The global war against intestinal parasites-should we use a holistic approach? Int J Infect Dis. 2010;14:e732-8.

22. Sartorius $B$, Legge $H$, Pullan R. Does suboptimal household flooring increase the risk of diarrhoea and intestinal parasite infection in low and middle income endemic settings? A systematic review and meta-analysis protocol. Syst Rev. 2020;9:113.

23. Koyuncu A, Dufour M-SK, Watadzaushe C, Dirawo J, Mushavi A, Padian N, et al. Household flooring associated with reduced infant diarrhoeal illness in Zimbabwe in households with and without WASH interventions. Trop Med Int Health. 2020;25:635-43.

24. Worrell CM, Wiegand RE, Davis SM, Odero KO, Blackstock A, Cuéllar VM, et al. A Cross-Sectional Study of Water, Sanitation, and Hygiene-Related Risk Factors for Soil-Transmitted Helminth Infection in Urban School- and Preschool-Aged Children in Kibera, Nairobi. PLOS ONE. Public Library of Science; 2016;11:e0150744.

25. Benjamin-Chung J, Nazneen A, Halder AK, Haque R, Siddique A, Uddin MS, et al. The Interaction of Deworming, Improved Sanitation, and Household Flooring with Soil-Transmitted Helminth Infection in Rural Bangladesh. Lv S, editor. PLoS Negl Trop Dis. 2015;9:e0004256.

26. Earth Enable - Projectenportfolio [Internet]. [cited 2021 Apr 1]. Available from: https://projectenportfolio.nl/wiki/index.php/PR_00235

27. Environmental and socio-demographic individual, family and neighborhood factors associated with children intestinal parasitoses at Iguazú, in the subtropical northern border of Argentina [Internet]. [cited 2021 Mar 31]. Available from: https://journals.plos.org/plosntds/article?id = 10.1371/journal.pntd.0006098

28. Conan A, O'Reilly CE, Ogola E, Ochieng JB, Blackstock AJ, Omore R, et al. Animal-related factors associated with moderate-to-severe diarrhea in children younger than five years in western Kenya: A 
matched case-control study. PLoS Negl Trop Dis. Public Library of Science; 2017;11:e0005795.

29. Melese B, Paulos W, Astawesegn FH, Gelgelu TB. Prevalence of diarrheal diseases and associated factors among under-five children in Dale District, Sidama zone, Southern Ethiopia: a cross-sectional study. BMC Public Health. 2019;19:1235.

30. Sinmegn Mihrete T, Asres Alemie G, Shimeka Teferra A. Determinants of childhood diarrhea among underfive children in Benishangul Gumuz Regional State, North West Ethiopia. BMC Pediatr. 2014;14:102.

31. H. Goldstein, Multilevel Statistical Models, vol. 922, John Wiley \& Sons, 2011. [Internet]. [cited 2021 Apr 24]. Available from: https://books.google.com.et/books?hl = en\&lr = \&id = mdwt7ibSGUYC\&oi $=$ fnd\&pg = PP14\&dq = H.+Goldstein,+Multilevel+Statistical+Models,+vol.+922,+John+Wiley+\%26+Sons,+2011.\&ots = fzLvG5LO0_\&sig = ntSpcaJjK4EL16n526Dnc0jnRXg\&redir_esc $=y \# v=$ onepage\&q\&f $=$ false

32. Hosmer DW, Lemeshow S, Sturdivant RX. Applied logistic regression. New York: John Wiley \& Sons, Incorporated, 2013.

33. Claudine U, Kim JY, Kim E-M, Yong T-S. Association between Sociodemographic Factors and Diarrhea in Children Under 5 Years in Rwanda. Korean J Parasitol. Korean Society for Parasitology; 2021;59:61.

34. Irfan M, Zaidi SMH, Waseem HF. Association of socio-demographic factors with diarrhea in children less than five years: a secondary analysis of multiple indicator cluster survey sindh 2014 . Pak j public health. 1970;7:85-9.

35. Azage M, Kumie A, Worku A, Bagtzoglou AC. Childhood diarrhea in high and low hotspot districts of Amhara Region, northwest Ethiopia: a multilevel modeling. J Health Popul Nutr. 2016;35:13.

36. Ali M, Asefaw T, Beyene H, Byass P, Shishay M, Hasibu MS, et al. A community-based study of childhood morbidity in Tigray, Northern Ethiopia. Ethiop J Health Dev. 2001;15:165-72.

37. Walker CLF, Perin J, Katz J, Tielsch JM, Black RE. Diarrhea as a risk factor for acute lower respiratory tract infections among young children in low income settings. J Glob Health [Internet]. 2013 [cited 2021 Apr 6];3. Available from: https://www.ncbi.nlm.nih.gov/pmc/articles/PMC3700029/

38. Schlaudecker EP, Steinhoff MC, Moore SR. Interactions of diarrhea, pneumonia, and malnutrition in childhood: recent evidence from developing countries. Curr Opin Infect Dis. 2011;24:496-502.

39. Bawankule R, Singh A, Kumar K, Pedgaonkar S. Disposal of children's stools and its association with childhood diarrhea in India. BMC Public Health. 2017;17:12.

40. Individual- and Community-Level Risk Factors Associated with Childhood Diarrhea in Ethiopia: A Multilevel Analysis of 2016 Ethiopia Demographic and Health Survey [Internet]. [cited 2021 Apr 24]. Available from: https://www.hindawi.com/journals/ijpedi/2021/8883618/

\section{Tables}


Table 1: Individual- and community-level variables included in the current study along with the coding and definitions. 

Variable description

\section{Format for analysis}

\section{Individual-level factors}

Child-related

factors

Child's sex

Categorized in to (1) female and (2) male

Child's age (in

Categorized into (1) 0-5; (2) 6-11; and (3) $\geq 12$

months)

Number of under- $\quad$ Categorized into (1) $0-1$; (2) 2-3; (3) >3

five children

Currently Categorized in to (1) Yes (2) No

breastfeeding

Birth order $\quad$ Categorized into (1) 1 ; (2) 2-3; (3) 4-5; and (4) 6+

Fever in the last Categorized in to (1) Yes (2) No

two-week

Cough $\quad$ Categorized in to (1) Yes (2) No

Child stool $\quad$ Categorized in to (1) Safe (2) Unsafe

disposal

Maternal/Parental

\& Household

factors

Mother's age (in Categorized into (1) 15-24; (2) 25-34; and (3) 35-49.

years)

Mother's

education level

Categorized into (1) No education (2) Primary \& above

Respondent

currently working

Paternal

education

Categorized in to (1) Yes (2) No

Respondent

occupation -

agriculture

employee

Partner occupation -

agriculture

employee

Watching Tv Categorized in to (1) Yes (2) No

Household size $\quad$ Categorized into (1) $1-4 ;(2) \geq 5$ 
Wealth quintiles Categorized in to (1) Poor; (2) Middle; and (3) Rich

Drinking water $\quad$ Categorized in to (1) Improved (2) Unimproved

sources

Sanitation Facility Categorized in to (1) Improved (2) Unimproved

Time to get to water source $<30$

Categorized into (1) On premise; (2) <30 min; and (3) >=30 min

minutes

Combined water \& sanitation facility

Categorized in to (1) Improved W + Improved T; (2) Improved W + Unimproved T;

(3) Unimproved W + Unimproved T; and (4) Unimproved W + Improved T

\section{Community-level}

factors

Place of residence Categorized into (1) Urban (2) Rural

Region $\quad$ Categorized into (1) Agrarian; (2) Pastoralist; and (3) City.

The variable was recoded as 'agrarian' (encompassing Tigray, Amhara, Oromia, Benishangul, SNNPR, and Gambela), 'pastoralist' (Afar and Somali regions) or 'city dweller' (Addis Ababa, Dire Dawa cites and Harari). An agrarian society is any community whose economy is based on producing and maintaining crops and farmland. A

pastoralist society is any community whose economy is based on raising livestock. A city-dweller society is any city community

Ecological

Cluster

Categorized into (1) <1500; (2) 1500-2500; and (3) >2500

Table 2: Socio-demographic, child, and parental characteristics of under-five children in Ethiopia. 
Child-related factors

Child's sex

\begin{tabular}{lll} 
Male & 4,646 & 51.1 \\
\hline Female & 4,451 & 48.9
\end{tabular}

Child's age (in months)

$\begin{array}{lll}0-5 & 1,035 & 11.6 \\ 6-11 & 887 & 10.0 \\ \geq 12 & 6,982 & 78.4\end{array}$

Number of under-five children

\begin{tabular}{lll}
$0-1$ & 3,243 & 35.6 \\
$2-3$ & 5,600 & 61.6 \\
\hline 3 & 254 & 2.8
\end{tabular}

Currently breastfeeding

\begin{tabular}{lll} 
Yes & 6,434 & 70.7 \\
\hline No & 2,662 & 29.3
\end{tabular}

Birth order

\begin{tabular}{lll}
1 & 1,554 & 17.1 \\
\hline $2-3$ & 2,699 & 29.7 \\
\hline $4-5$ & 2,282 & 25.1 \\
\hline $6+$ & 2,561 & 28.1
\end{tabular}

Fever in the last two-week

\begin{tabular}{lll} 
Yes & 1,314 & 14.5 \\
\hline No & 7,783 & 85.5
\end{tabular}

Cough

\begin{tabular}{lll} 
Yes & 7,260 & 20.2 \\
\hline No & 1,836 & 79.8
\end{tabular}

Diarrhea 
Child stool disposal

$\begin{array}{lll}\text { Safe } & 1,916 & 21.1 \\ \text { Unsafe } & 7,180 & 78.9\end{array}$

Parental factors

Mother's age (in years)

\begin{tabular}{lll}
$15-24$ & 2,044 & 22.4 \\
\hline $25-34$ & 4,753 & 52.3 \\
$35-49$ & 2,299 & 25.3
\end{tabular}

Mother's education level

No education

Primary \& above
6,400

2,696

2,304

6,792

No

No education

Primary \& above
4,490

4,114
70.4 29.6

Respondent currently working

Paternal education $(n=8,604)$

Yes

6,838

75.2

No

2,259

Partner occupation - agriculture employee

\begin{tabular}{lll} 
Yes & 6,166 & 67.8 \\
\hline No & 2,930 & 32.2
\end{tabular}

Watching Tv

$\begin{array}{lll}\text { Yes } & 1,081 & 11.9 \\ \text { No } & 8,016 & 88.1\end{array}$


Household factors

Household size

$\begin{array}{lll}1-4 & 2,212 & 24.1 \\ \geq 5 & 6,884 & 75.9\end{array}$

Place of residence

\begin{tabular}{lll} 
Urban & 416 & 4.6 \\
\hline Rural & 8,681 & 95.4
\end{tabular}

Wealth quintiles

\begin{tabular}{lll} 
Poor & 4,812 & 52.9 \\
\hline Middle & 2,060 & 22.6 \\
\hline Rich & 2,223 & 24.4
\end{tabular}

Drinking water sources

$\begin{array}{lll}\text { Improved } & 4,276 & 47.7 \\ \text { Unimproved } & 4,689 & 52.3\end{array}$

Time to get to water source $<30$

minutes

$\begin{array}{lll}\text { On-premise } & 454 & 5.1 \\ <30 \mathrm{~min} & 3,570 & 39.9 \\ >=30 \mathrm{~min} & 4,927 & 55.0\end{array}$

Sanitation Facility

$\begin{array}{lll}\text { Improved } & 497 & 5.5 \\ \text { Unimproved } & 8,468 & 94.5\end{array}$

Combined water \& sanitation facility $(n=8,965)$

\begin{tabular}{lcc} 
Improved W + Improved T & 311 & 3.5 \\
$\begin{array}{l}\text { Improved W + } \\
\text { Unimproved T }\end{array}$ & 4,378 & 48.8 \\
$\begin{array}{l}\text { Unimproved W + } \\
\text { Unimproved T }\end{array}$ & 4,089 & 45.6 \\
$\begin{array}{l}\text { Unimproved W + } \\
\text { Improved T }\end{array}$ & 186 & 2.1 \\
\hline
\end{tabular}

Region 


\begin{tabular}{|llll|} 
& Agrarian & 8,567 & 94.2 \\
\hline Pastoralist & 485 & 5.3 \\
\hline Ecological Cluster & City & 44 & 0.5 \\
\hline & & & \\
\hline & 1500 & 1,628 & 17.9 \\
\hline & $1500-2500$ & 6,248 & 68.7 \\
\hline
\end{tabular}

${ }^{a}$ child who received one dose of measles vaccine at any time before the survey (according to a vaccination card, health facility, or the mother's report); ${ }^{b}$ frequency of watching television was categorized as yes (less than once a week, at least once a week, and almost every day) and no (not at all).

Table 3: Multilevel bivariate logistic regression analysis of the prevalence of diarrhea among children in households with sub-optimal flooring by different background characteristics and associated factors. 


\section{Variables}

\section{Variables}

Child-related factors

Child's sex

$\begin{array}{lllll}\text { Male } & 572 & 4,074 & 1 & \\ \text { Female } & 509 & 3,941 & 0.89(0.77-1.02) & 0.106\end{array}$

Child's age (in months)

\begin{tabular}{lllll}
$0-5$ & 956 & 78 & 1 & \\
\hline $6-11$ & 692 & 195 & $3.18(2.31-4.37)^{\star}$ & $p<0.001$ \\
$\geq 12$ & 6,191 & 791 & $1.51(1.15-1.98)^{\star}$ & 0.003 \\
\hline
\end{tabular}

Number of under-five children

\begin{tabular}{lllll}
$0-1$ & 2,755 & 488 & 1 & \\
\hline $2-3$ & 5,013 & 587 & $0.79(0.68-0.92)^{\star}$ & 0.002 \\
\hline$>3$ & 247 & 6 & $0.73(0.45-1.18)$ & 0.210 \\
\hline
\end{tabular}

Currently breastfeeding

$\begin{array}{lllll}\text { Yes } & 823 & 5,611 & 1 & \\ \text { No } & 259 & 2,403 & 0.75(0.64-0.88)^{\star} & p<0.001\end{array}$

Birth order

\begin{tabular}{lllll}
1 & 1,348 & 206 & $1.10(0.88-1.38)$ & 0.395 \\
\hline $2-3$ & 2,364 & 335 & $1.15(0.95-1.39)$ & 0.158 \\
\hline $4-5$ & 2,003 & 279 & $1.18(0.97-1.44)$ & 0.098 \\
\hline $6+$ & 2,300 & 261 & 1 & \\
\hline
\end{tabular}

Fever in the last two-week

$\begin{array}{lrrll}\text { Yes } & 493 & 821 & \begin{array}{l}8.74(7.42- \\ 10.29)\end{array} & p<0.001 \\ \text { No } & 588 & 7,194 & 1\end{array}$

Cough in the last two-week

$\begin{array}{lllll}\text { Yes } & 487 & 1,349 & 4.65(3.97-5.46)^{*} & p<0.001 \\ \text { No } & 595 & 6,665 & 1\end{array}$


Child stool disposal

$\begin{array}{lllll}\text { Safe } & 281 & 1,635 & 1 & \\ \text { Unsafe } & 800 & 6,379 & 0.71(0.59-0.85)^{\star} & p<0.001\end{array}$

Parental factors

Mother's age (in years)

\begin{tabular}{lllll}
$15-24$ & 276 & 1,767 & $1.37(1.11-1.70) *$ & 0.003 \\
\hline $25-34$ & 580 & 4,174 & $1.28(1.06-1.54) *$ & 0.009 \\
\hline $35-49$ & 226 & 2,073 & 1 & \\
\end{tabular}

Mother's education level

\begin{tabular}{|lrlll|}
$\begin{array}{l}\text { No } \\
\text { education }\end{array}$ & 723 & 5,677 & $0.81(0.69-0.95)^{\star}$ & 0.011 \\
\hline $\begin{array}{l}\text { Primary \& } \\
\text { above }\end{array}$ & 358 & 2,338 & 1 & \\
\hline
\end{tabular}

Respondent currently working

\begin{tabular}{lllll} 
Yes & 313 & 1,991 & $1.22(1.03-1.44)^{*}$ & 0.018 \\
\hline No & 768 & 6,024 & 1 & \\
\hline
\end{tabular}

Paternal education

\begin{tabular}{lllll}
$\begin{array}{l}\text { No } \\
\text { education }\end{array}$ & 464 & 4,026 & $0.70(0.60-0.82)^{*}$ & $\mathrm{p}<0.001$ \\
\hline $\begin{array}{l}\text { Primary \& } \\
\text { above }\end{array}$ & 548 & 3,567 & 1 &
\end{tabular}

Respondent occupation agriculture employee

\begin{tabular}{lllll} 
Yes & 274 & 1,985 & $0.98(0.82-1.18)$ & 0.897 \\
\hline No & 808 & 6,030 & 1 &
\end{tabular}

Partner occupation - agriculture employee

\begin{tabular}{lllll} 
Yes & 705 & 5,461 & $0.93(0.79-1.08)$ & 0.345 \\
\hline No & 376 & 2,554 & 1 & \\
\hline
\end{tabular}

Watching TV

\begin{tabular}{lllll} 
Yes & 133 & 948 & $1.12(0.87-1.40)$ & 0.400 \\
\hline No & 949 & 7,067 & 1 & \\
\hline
\end{tabular}


Household factors

Household size

$\begin{array}{lllll}1-4 & 322 & 1,890 & 1 & \\ \geq 5 & 760 & 6,124 & 0.83(0.70-0.97)^{*} & 0.021\end{array}$

Place of residence

$\begin{array}{lllll}\text { Urban } & 49 & 367 & 1 & \\ \text { Rural } & 1,032 & 7,648 & 0.89(0.65-1.22) & 0.478\end{array}$

Wealth quintiles

\begin{tabular}{lllll} 
Poor & 534 & 4,278 & $0.82(0.67-0.99) *$ & 0.046 \\
\hline Middle & 260 & 1,799 & $0.97(0.76-1.23)$ & 0.796 \\
\hline Rich & 286 & 1,937 & 1 & \\
\hline
\end{tabular}

Drinking water sources

$\begin{array}{lrrll}\text { Improved } & 559 & 4,130 & 1 & \\ \text { Unimproved } & 495 & 3,780 & 0.98(0.83-1.15) & 0.808\end{array}$

Time to get to water source $<30$

minutes

Yes

No

Sanitation Facility

Yes

No

Improved

Unimproved

Unimproved $\mathrm{W}+$ Unimproved $\mathrm{T}$

$\begin{array}{lll}46 & 7.458 \quad 1\end{array}$

1,009

1

$0.92(0.79-1.08) \quad 0.309$

\begin{tabular}{lllll} 
Agrarian & 1,041 & 7,526 & $0.91(0.65-1.28)$ & 0.612 \\
\hline Pastoralist & 36 & 449 & $0.57(0.38-0.83)^{\star}$ & 0.004 \\
\hline City & 5 & 39 & 1 &
\end{tabular}

Ecological Cluster

$\begin{array}{llll}<1500 & 183 & 1,445 \quad 1\end{array}$




\begin{tabular}{lllll}
$1500-2500$ & 775 & 5,472 & $1.25(1.03-1.51) *$ & 0.023 \\
\hline 2500 & 123 & 1,097 & $1.01(0.71-1.45)$ & 0.944
\end{tabular}

${ }^{*} p$-value $<0.05$ (un adjusted OR)

Table 4: Results of multivariable multilevel logistic regression analysis of factors associated with childhood diarrhea among households with sub-optimal flooring. 


\begin{tabular}{|c|c|c|c|c|c|}
\hline Variables & Category & $\begin{array}{l}\text { Empty } \\
\text { Model } \\
\text { adjusted } \\
\text { OR } \\
(95 \% \mathrm{Cl})\end{array}$ & $\begin{array}{l}\text { Model } 1 \\
\text { adjusted } \\
\text { OR } \\
(95 \% \mathrm{Cl})\end{array}$ & $\begin{array}{l}\text { Model } 2 \\
\text { adjusted } \\
\text { OR } \\
(95 \% \mathrm{Cl})\end{array}$ & $\begin{array}{l}\text { Model } 3 \\
\text { adjusted } \\
\text { OR } \\
(95 \% \mathrm{Cl})\end{array}$ \\
\hline \multicolumn{6}{|c|}{ Child-related factors } \\
\hline \multicolumn{6}{|l|}{ Child's sex } \\
\hline & Male & & 1 & & 1 \\
\hline & Female & & $\begin{array}{l}0.89 \\
(0.76- \\
1.05)\end{array}$ & & $\begin{array}{l}0.89 \\
(0.75- \\
1.04)\end{array}$ \\
\hline \multicolumn{6}{|c|}{ Child's age (in months) } \\
\hline & $0-5$ & & 1 & & 1 \\
\hline & $6-11$ & & $\begin{array}{l}2.68 \\
(1.88- \\
3.81)^{\star \star}\end{array}$ & & $\begin{array}{l}2.68 \\
(1.89- \\
3.82)^{\star \star \star}\end{array}$ \\
\hline & $\geq 12$ & & $\begin{array}{l}1.67 \\
(1.23- \\
2.26)^{\star \star}\end{array}$ & & $\begin{array}{l}1.65 \\
(1.22- \\
2.24)^{\star \star}\end{array}$ \\
\hline \multicolumn{6}{|c|}{ Number of under-five children } \\
\hline & $0-1$ & & 1 & & 1 \\
\hline & $2-3$ & & $\begin{array}{l}0.79 \\
(0.65- \\
0.96)^{\star \star}\end{array}$ & & $\begin{array}{l}0.80 \\
(0.66- \\
0.98)^{\star \star}\end{array}$ \\
\hline & $>3$ & & $\begin{array}{l}0.67 \\
(0.39- \\
1.14)\end{array}$ & & $\begin{array}{l}0.70 \\
(0.41- \\
1.20)\end{array}$ \\
\hline \multicolumn{6}{|c|}{ Currently breastfeeding } \\
\hline & Yes & & 1 & & 1 \\
\hline & No & & $\begin{array}{l}0.83 \\
(0.68- \\
1.01)\end{array}$ & & $\begin{array}{l}0.85 \\
(0.69- \\
1.03)\end{array}$ \\
\hline \multicolumn{6}{|l|}{ Birth order } \\
\hline & 1 & & $\begin{array}{l}0.54 \\
(0.36- \\
0.80)^{\star \star}\end{array}$ & & $\begin{array}{l}0.53 \\
(0.36- \\
0.79)^{\star \star}\end{array}$ \\
\hline & $2-3$ & & $\begin{array}{l}0.83 \\
(0.62- \\
1.09)\end{array}$ & & $\begin{array}{l}0.81 \\
(0.61- \\
1.07)\end{array}$ \\
\hline
\end{tabular}




$\begin{array}{ccc}4-5 & 1.05 & 1.04 \\ & (0.83- & (0.82- \\ & 1.34) & 1.33) \\ 6+ & 1 & 1\end{array}$

Fever in the last two-week

$\begin{array}{lll}\text { Yes } & 6.10 & 6.09 \\ & (4.93- & (4.93- \\ & 7.53)^{\star \star} & 7.52)^{\star \star \star} \\ \text { No } & 1 & 1\end{array}$

Cough in the last two-week

$\begin{array}{lll}\text { Yes } & 1.62 & 1.62 \\ & (4.93- & (1.30- \\ & 7.53)^{\star \star} & 2.01)^{\star \star \star} \\ \text { No } & 1 & 1\end{array}$

Child stool disposal

$\begin{array}{lll}\text { Safe } & 1 & 1 \\ \text { Unsafe } & 0.71 & 0.71 \\ & (0.57- & (0.57- \\ & 0.87)^{\star \star} & 0.87)^{\star \star}\end{array}$

\section{Parental factors}

Mother's age (in years)

\begin{tabular}{lll}
$15-24$ & 1.34 & 1.39 \\
& $(0.95-$ & $(0.98-$ \\
& $1.90)$ & $1.98)$ \\
$25-34$ & 1.29 & 1.32 \\
& $(1.01-$ & $(1.03-$ \\
& $1.66)^{\star \star}$ & $1.69)^{\star \star}$ \\
\hline $35-49$ & 1 &
\end{tabular}

Mother's education level

\begin{tabular}{lll} 
No & 1.05 & 1.07 \\
education & $(0.85-$ & $(0.87-$ \\
& $1.29)$ & $1.33)$ \\
\hline $\begin{array}{l}\text { Primary \& } \\
\text { above }\end{array}$ & 1 & 1
\end{tabular}

Respondent currently working

$\begin{array}{lll}\text { Yes } & 1.08 & 1.06 \\ & (0.89- & (0.88- \\ & 1.31) & 1.28)\end{array}$


Paternal education

\begin{tabular}{lll} 
No & 0.79 & 0.82 \\
education & $(0.66-$ & $(0.68-$ \\
& $0.96)^{\star \star}$ & $0.99)^{\star \star}$ \\
\hline $\begin{array}{l}\text { Primary \& } \\
\text { above }\end{array}$ & 1 & 1
\end{tabular}

Household factors

Household size

$\begin{array}{lll}1-4 & 1 & 1 \\ \geq 5 & 0.67 & 0.66 \\ & (0.53- & (0.52- \\ & 0.85)^{\star \star} & 0.85)^{\star \star}\end{array}$

Wealth quintiles

$\begin{array}{lll}\text { Poor } & 0.91 & 0.95 \\ & (0.72- & (0.73- \\ & 1.15) & 1.21) \\ \text { Middle } & 0.96 & 0.96 \\ & (0.73- & (0.73- \\ & 1.26) & 1.27) \\ \text { Rich } & 1 & 1\end{array}$

Drinking water sources

$\begin{array}{lll}\text { Improved } & 1 & 1 \\ \text { Unimproved } & 0.92 & 0.99 \\ & (0.45- & (0.49- \\ & 1.85) & 1.99)\end{array}$

Time to get to water source $<30$ minutes

$\begin{array}{lll}\text { Yes } & 1 & 1 \\ \text { No } & 0.98 & 1.01 \\ & (0.83- & (0.85- \\ & 1.17) & 1.20)\end{array}$

Sanitation Facility

$\begin{array}{lll}\text { Improved } & 1 & 1 \\ \text { Unimproved } & 0.93 & 0.93 \\ & (0.64- & (0.64- \\ & 1.34) & 1.35)\end{array}$

Household with unimproved 
water and toilet facility

$\begin{array}{lll}\text { Yes } & 1 & 1 \\ \text { No } & 0.79 & 0.82 \\ & (0.38- & (0.40- \\ & 1.62) & 1.69)\end{array}$

Place of residence

$\begin{array}{lll}\text { Urban } & 1 & 1 \\ \text { Rural } & 0.87 & 0.88 \\ & (0.64- & (0.60- \\ & 1.19) & 1.29)\end{array}$

Region

$\begin{array}{lll}\text { Agrarian } & 0.94 & 0.79 \\ & (0.67- & (0.55- \\ & 1.33) & 1.12) \\ \text { Pastoralist } & 0.58 & 0.61 \\ & (0.39- & (0.40- \\ & 0.87)^{\star \star} & 0.91)^{\star \star} \\ \text { City } & 1 & 1\end{array}$

Ecological Cluster

$\begin{array}{lll}<1500 & 1 & 1 \\ 1500-2500 & 1.03 & 1.03 \\ & (0.84- & (0.82- \\ >2500 & 1.28) & 1.28) \\ & 0.82 & 0.69 \\ & (0.56- & (0.46- \\ & 1.19) & 1.03)\end{array}$

${ }^{*} \mathrm{p}<0.05$ (unadjusted OR), ** $\mathrm{p}<0.05$ (adjusted OR)

Table 5: Results of condensed model (model 3): multilevel mixed-effect logistic regression analysis of childhood diarrhea among households with sub-optimal flooring. 
Variables

Category
Model 3

adjusted OR (95\% Cl)

Child-related factors

Age

0-5

6-11

$\geq 12$

1

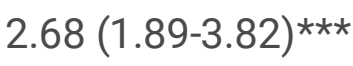

$1.65(1.22-2.24)^{\star *}$

Number of under-five children

$\begin{array}{ll}0-1 & 1 \\ 2-3 & 0.80(0.66-0.98) \star \star \\ >3 & 0.70(0.41-1.20)\end{array}$

Birth order

1

2-3

$0.53(0.36-0.79)$ **

4-5

$0.81(0.61-1.07)$

$6+$

$1.04(0.82-1.33)$

1

Fever in the last two-week

$\begin{array}{ll}\text { Yes } & 6.09(4.93-7.52)^{\star \star \star} \\ \text { No } & 1\end{array}$

Cough in the last two-week

$\begin{array}{ll}\text { Yes } & 1.62(1.30-2.01)^{\star \star \star} \\ \text { No } & 1\end{array}$

Child stool disposal

$\begin{array}{ll}\text { Safe } & 1 \\ \text { Unsafe } & 0.71(0.57-0.87)^{\star \star}\end{array}$

Parental factors

Mother's age (in years)

$\begin{array}{ll}15-24 & 1.39(0.98-1.98) \\ 25-34 & 1.32(1.03-1.69)^{\star *} \\ 35-49 & \end{array}$


Paternal education

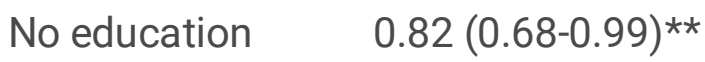

Primary \& above 1

Household factors

Household size

$\begin{array}{ll}1-4 & 1 \\ \geq 5 & 0.66(0.52-0.85)^{\star \star}\end{array}$

Drinking water sources

Improved $\quad 1$

Unimproved $\quad 0.99(0.49-1.99)$

Sanitation facility

Improved $\quad 1$

Unimproved $\quad 0.93(0.64-1.35)$

Household with unimproved water and toilet facility

Yes

No

$0.82(0.40-1.69)$

Region

$\begin{array}{ll}\text { Agrarian } & 0.79(0.55-1.12) \\ \text { Pastoralist } & 0.61(0.40-0.91)^{\star \star} \\ \text { City } & 1\end{array}$

${ }^{\star} \mathrm{p}<0.05$ (unadjusted OR ), ** $\mathrm{p}<0.05$ (adjusted OR)

Table 6: Model comparison to determine factors associated with childhood diarrhea in households with sub-optimal flooring. 


\begin{tabular}{|c|c|c|c|c|}
\hline $\begin{array}{l}\text { Individual- and community-level } \\
\text { characteristics }\end{array}$ & $\begin{array}{l}\text { Null model } \\
\text { (Empty } \\
\text { mode) }\end{array}$ & Model 1 & Model 2 & Model 3 \\
\hline \multicolumn{5}{|l|}{ Random effect } \\
\hline Community-level variance (SE) & $\begin{array}{l}0.380 \\
(0.0034)\end{array}$ & $\begin{array}{l}0.231 \\
(0.0054)\end{array}$ & $\begin{array}{l}0.332 \\
(0.0034)\end{array}$ & $\begin{array}{l}0.210 \\
(0.0055)\end{array}$ \\
\hline ICC (\%) & 10.36 & 6.57 & 9.17 & 6.00 \\
\hline $\mathrm{MOR}^{\mathrm{e}}$ & 1.79 & 1.58 & 1.73 & 1.54 \\
\hline PCV (\%) & Reference & $39.2 \%$ & $12.6 \%$ & $44.7 \%$ \\
\hline \multicolumn{5}{|l|}{ Model fit statistics } \\
\hline AIC & $5,605.52$ & $4,438.73$ & $5,594.64$ & 4437.15 \\
\hline $\mathrm{BIC}$ & $5,619.51$ & $4,618.09$ & $5,643.62$ & 4651.01 \\
\hline DIC(-2Log-likelihood) & $5,601.52$ & $4,386.73$ & $5,580.64$ & $4,375.15$ \\
\hline
\end{tabular}

Null Model (Empty model) was fitted without determinant variables

Model 1 is adjusted for individual-level variables

Model 2 is adjusted for community-level variables

Model 3 is the final model adjusted for individual- and community-level variables

SE Standard Error; ICC: Intra-class Correlation Coefficient; MOR: Median Odds Ratio; AIC: Akaike's Information Criterion; BIC: Bayesian information Criteria; DIC: Deviance Information Criterion.

\section{Figures}


Ethiopian Demographic \& Health Survey (EDHS)-2016

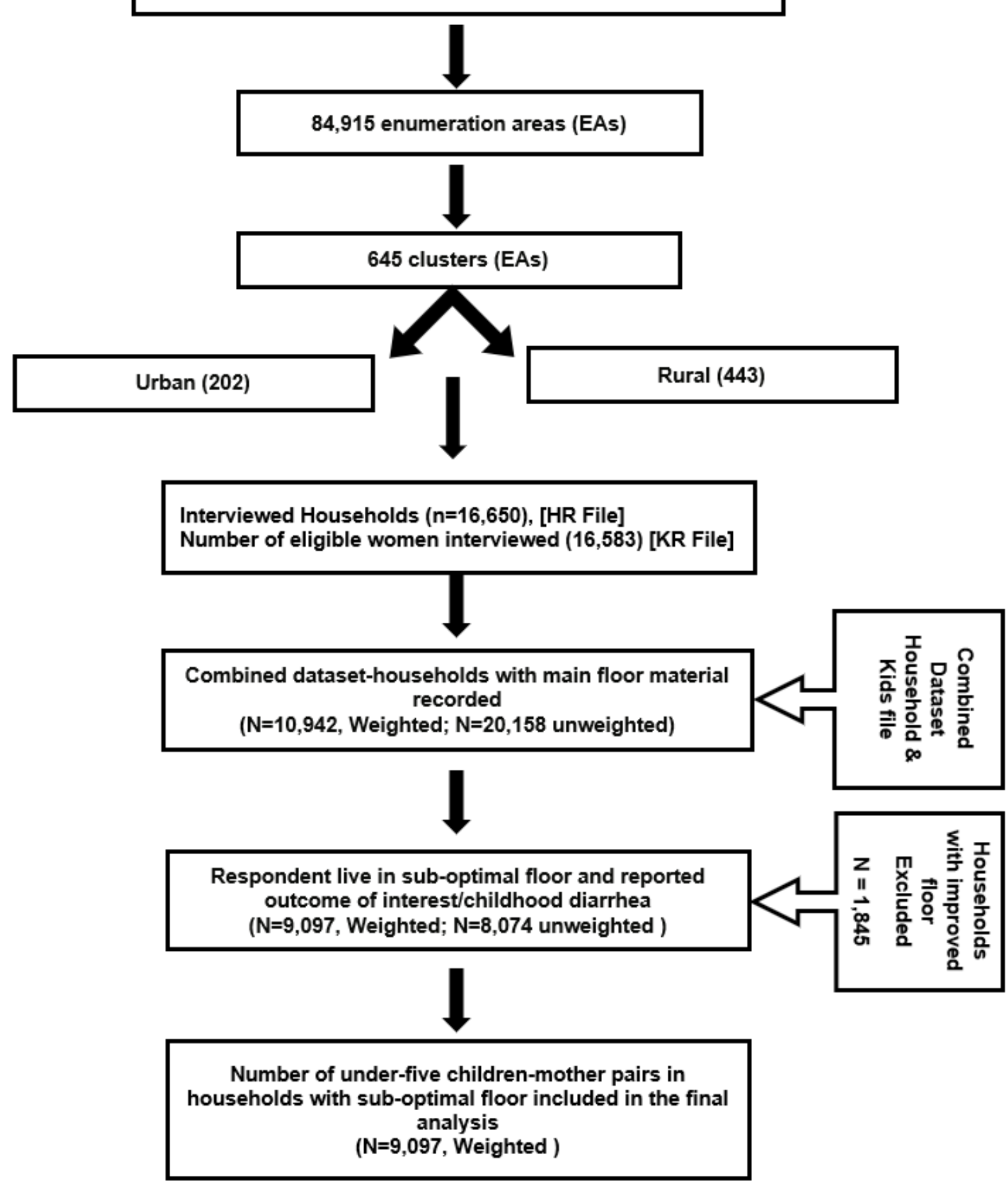

Figure 1

Schematic diagram of study participant selection 